\title{
Study of Enzymes in Myocardial Infarction
}

\author{
Sudha Rani Yeluri* \\ Consultant Endocrinologist and Diabetologist, Department of Bio-Chemistry, Kurnool Medical College, India \\ ${ }^{*}$ Corresponding author: Sudha Rani Yeluri, Consultant Endocrinologist and Diabetologist, Department of \\ Bio-Chemistry, Kurnool Medical College, India, E-mail: drysudharani@gmail.com \\ Citation: Sudha Rani Yeluri (2018) Study of Enzymes in Myocardial Infarction. J Clin Exp Res Cardiol 4(1): \\ 106
}

Received Date: April 28, 2018 Accepted Date: June 20, 2018 Published Date: June 22, 2018

\section{Introduction}

The term Myocardial infarction signifies sudden necrosis or death of a portion of cardiac muscle due to inadequate blood supply [1]. Myocardial infarction results from prolonged myocardial coronary thrombus at the site of a pre-existing atherosclerotic stenosis [2]. The major cause of acute myocardial infarction is atherosclerosis [3]. It is three to four times more frequent among men than women [4].

Acute myocardial infarction also known as "heart attack" is the most important form of ischaemic heart disease in industrial nations and is the leading cause of death in UK. In myocardial infarction half of the deaths occur within one hour of the events and are attributed to arrhythmias, due to ventricular fibrillation [5]. The death rate from acute myocardial infarction has declined by about $30 \%$ over the last decade [6]. Coronary artery disease is the greatest killer of mankind. Coronary heart disease in its various forms accounts for about $75 \%$ of deaths caused by heart disease. Coronary heart disease is the commonest form of heart disease and is the single most important cause of premature death in the developed countries. Now it is becoming more common in developing countries like India [7].

\section{Ischaemic Heart Disease}

Ischaemic heart disease is defined by the "World Health Organization" (WHO, 1979) as myocardial impairment due to imbalance between the supply and demand of the heart for oxygenated blood. The term IHD is synonymous with the term Coronary artery disease $(\mathrm{CAD})$ or coronary heart disease $(\mathrm{CHD})[8]$.

Coronary artery disease represents a spectrum of conditions with acute transmural infarction at one end of the spectrum, ranging successively through non transmural infarction, Unstable Angina and chronic stable angina to silent ischaemia at other end [9].

\section{Myocardial Infarction}

Myocardial infarction is either a) acute myocardial infarction b) chronic myocardial infarction.

Complications of myocardial infarction are,

1. Sudden death, 2. Uncomplicated cases, and 3. Complicated cases

Complications associated with myocardial infarction are,

a) Cardiac arrhythmias, b) Left ventricle congestive failure, c) Cardiogenic shock and d) Thromboembolism

Sudden Cardiac Death: Most commonly sudden cardiac death is defined as unexpected death from cardiac causes within one hour of the onset of acute symptoms [10].

Coronary artery disease is posing a major health challenge in India. Prevalence of coronary artery disease in India is $10 / 1000$ to $126 / 1000$. In Indians coronary artery disease (CAD) commonly manifests as acute myocardial infarction without prior angina. By $2015 \mathrm{AD}$, coronary artery disease will account for $34 \%$ of all male deaths and $32 \%$ of all female deaths in India Lifestyle changes related to diet, mechanization, increased sedentary outlook, increase in serum cholesterol, hypertension, insulin resistance, obesity and dyslipidemia are responsible for this increase (Table 1). Asian Indians have the highest rates of mortality from coronary artery disease amongst all ethnic groups studied so far and the coronary artery disease in them is often premature and follows a malignant course [11].

It has become necessary to achieve early diagnosis the causes of myocardial infarction, to assess the effectiveness of treatment, and to predict prognosis. So serial estimations of plasma enzymes in course of myocardial infarction are of greatest value in diagnosing 
and predicting the prognosis in these patients $[12,13]$.

In conclusion myocardial infarction is a major public health problem and the need remains to prevent myocardial infarction by avoiding the modifiable risk factors [14].

\begin{tabular}{|c|c|c|c|c|c|c|}
\hline S.No & CK & CK-MB & LDH & LDH-1 & LDH-2 & AST \\
\hline $\mathbf{1}$ & 32.2 & 1.3 & 263 & 63.7 & 28 & 92 \\
\hline $\mathbf{2}$ & 29.6 & 1.2 & 160 & 43.2 & 24 & 56 \\
\hline $\mathbf{3}$ & 66.5 & 2 & 315 & 85 & 43.5 & 110.3 \\
\hline $\mathbf{4}$ & 52.8 & 1.6 & 225 & 60.8 & 34.1 & 78.8 \\
\hline $\mathbf{5}$ & 100.3 & 3 & 203 & 54.8 & 32 & 71 \\
\hline $\mathbf{6}$ & 69.9 & 2.1 & 231.9 & 62.6 & 31.1 & 81.2 \\
\hline $\mathbf{7}$ & 125 & 3.8 & 241 & 65 & 35 & 84.4 \\
\hline $\mathbf{8}$ & 203 & 6 & 223.7 & 60.4 & 36.4 & 78.3 \\
\hline $\mathbf{9}$ & 225 & 6.8 & 280.9 & 51.8 & 51.8 & 98.3 \\
\hline $\mathbf{1 0}$ & 43 & 1.3 & 191.9 & 90.8 & 28.3 & 67.2 \\
\hline $\mathbf{1 1}$ & 163 & 4.9 & 324.6 & 58.3 & 33.1 & 113.6 \\
\hline $\mathbf{1 2}$ & 163 & 4.9 & 208.3 & 55 & 31.5 & 72.9 \\
\hline $\mathbf{1 3}$ & 169 & 5 & 196.7 & 86.7 & 25 & 68.8 \\
\hline $\mathbf{1 4}$ & 198 & 5.9 & 309.8 & 92.1 & 23.5 & 115.2 \\
\hline $\mathbf{1 5}$ & 200 & 6 & 329 & 60.8 & 34.3 & 78.8 \\
\hline $\mathbf{1 6}$ & 205 & 6.2 & 225 & 114.2 & 28 & 148 \\
\hline $\mathbf{1 7}$ & 192 & 5.8 & 423 & 61.6 & 55.9 & 77 \\
\hline $\mathbf{1 8}$ & 200 & 6 & 329.6 & 71.4 & 25 & 89.3 \\
\hline $\mathbf{1 9}$ & 103 & 3.1 & 219.9 & 55 & 32 & 56 \\
\hline $\mathbf{2 0}$ & 154 & 4.6 & 255 & 65 & 30.6 & 71 \\
\hline $\mathbf{S D}$ & 70.3 & 2.5 & 82.5 & 17.6 & 10.9 & 4.4 \\
\hline $\mathbf{M E A N}$ & 134.7 & 3 & 257.8 & 70.2 & 33.2 & 90.2 \\
\hline $\mathbf{a b}$ & $\mathbf{2}$ & $\mathbf{5}$ & \\
\hline
\end{tabular}

Table 1: Serial serum enzyme estimations in controls (Units per Litre)

The present study is carried out to compare the enzymes (Total creatine kinase, creatine kinase MB, total lactate dehydrogenase, lactate dehydrogenase-1, lactate dehydrogenase-2 and aspartate-aminotransferase) in myocardial infarction with normal subjects (Table 2) [12].

\begin{tabular}{|c|c|c|c|c|c|}
\hline S.NO & T.CHOL & HDL.C & TG & LDL.C & VLDL.C \\
\hline $\mathbf{1}$ & 162 & 54 & 128 & 82.4 & 25.6 \\
\hline $\mathbf{2}$ & 183 & 60 & 104 & 102.2 & 20.8 \\
\hline $\mathbf{3}$ & 226 & 65 & 132 & 134.6 & 26.4 \\
\hline $\mathbf{4}$ & 242 & 72 & 147 & 140.6 & 29.4 \\
\hline $\mathbf{5}$ & 180 & 68 & 104 & 91.2 & 20.8 \\
\hline $\mathbf{6}$ & 214 & 80 & 152.7 & 103.6 & 30.54 \\
\hline $\mathbf{7}$ & 160 & 32 & 128 & 102.4 & 25.6 \\
\hline $\mathbf{8}$ & 267 & 53 & 147 & 184.6 & 29.4 \\
\hline $\mathbf{9}$ & 168 & 32 & 134 & 109.2 & 26.8 \\
\hline $\mathbf{1 0}$ & 194 & 39 & 128.6 & 129.28 & 25.72 \\
\hline $\mathbf{1 1}$ & 243 & 42 & 147 & 171.6 & 29.4 \\
\hline $\mathbf{1 2}$ & 210 & 58 & 152.7 & 121.46 & 30.54 \\
\hline $\mathbf{1 3}$ & 200 & 40 & 128.6 & 134.28 & 25.72 \\
\hline $\mathbf{1 4}$ & 280 & 48 & 147 & 202.6 & 29.4 \\
\hline $\mathbf{1 5}$ & 175 & 26 & 101 & 128 & 20.2 \\
\hline $\mathbf{1 6}$ & 220 & 28 & 144.8 & 163.04 & 28.96 \\
\hline $\mathbf{1 7}$ & 215 & 53 & 98.4 & 142.32 & 19.68 \\
\hline $\mathbf{1 8}$ & 163 & 62 & 134 & 74.2 & 26.8 \\
\hline $\mathbf{1 9}$ & 192 & 64 & 128.6 & 128.28 & 25.72 \\
\hline
\end{tabular}




\begin{tabular}{|c|c|c|c|c|c|}
\hline S.NO & T.CHOL & HDL.C & TG & LDL.C & VLDL.C \\
\hline $\mathbf{2 0}$ & 235 & 38 & 144.8 & 168.04 & 28.96 \\
\hline SD & 34.8 & 15.43 & 17.49 & 38.44 & 3.5 \\
\hline MEAN & 206 & 50.7 & 131.6 & 130.73 & 26.32 \\
\hline
\end{tabular}

Table 2: Lipid profile in controls $(\mathrm{mg} / \mathrm{dl})$

The enzyme study in myocardial infarction is done by a number of research workers. My aim is to study the enzymes so as to correlate my findings with earlier findings (Table 3).

\begin{tabular}{|c|c|c|}
\hline S.NO & $\begin{array}{c}\text { 1st } \\
\text { DAY }\end{array}$ & $\begin{array}{c}\text { 3rd } \\
\text { DAY }\end{array}$ \\
\hline 1 & 250 & 220.3 \\
\hline 2 & 480 & 175 \\
\hline 3 & 398 & 283.9 \\
\hline 4 & 1795 & 45.68 \\
\hline 5 & 330 & 283.5 \\
\hline 6 & 2761 & 819 \\
\hline 7 & 2341 & 760 \\
\hline 8 & 1916 & 294 \\
\hline 9 & 591 & 190.7 \\
\hline 10 & 475 & 175.8 \\
\hline 11 & 385.8 & 205.8 \\
\hline 12 & 2770 & 174 \\
\hline 13 & 547.2 & 178 \\
\hline 14 & 477.4 & 188 \\
\hline 15 & 487.8 & 376.2 \\
\hline 16 & 517.7 & 120 \\
\hline 17 & 646.7 & 178 \\
\hline 18 & 800.5 & 296.4 \\
\hline 19 & 930.5 & 180 \\
\hline 20 & 320.2 & 182 \\
\hline 21 & 936 & 185 \\
\hline 22 & 2233 & 240 \\
\hline 23 & 1040 & 176 \\
\hline 24 & 1540 & 182 \\
\hline 25 & 1542 & 203 \\
\hline SD & 806.15 & 159 \\
\hline MEAN & 1060.5 & 252.5 \\
\hline
\end{tabular}

Table 3: Serial serum enzyme estimations of CK in patients with AMI

\section{Aim of Study}

The present study is done in patients suffering from acute Myocardial infarction [15].

Aim of this study is to assess the effectiveness of therapy in patients of acute myocardial infarction with the help of serial estimation of enzyme levels of,

1. Total creatine kinase.

2. Creatine kinase MB.

3. Total lactate dehydrogenase.

4. Lactate dehydrogenase isoenzyme LDH-1 and LDH-2.

5. Aspartate aminotransferase.

6. Lipid profile is done to evaluate risk factors (Table 2).

It is always better to detect the acute Myocardial infarction in very early stage by suitable cardiac markers, for better prevention and for management of complications. 


\section{Review of Literature}

\section{Atherosclerosis}

Atherosclerosis has been recognized in humans for thousands of years. Lesions of atherosclerosis were identified in Egyptian mummies as early as the 15 th century B. C. Long has discussed the development of clinicopathological correlation between the degree of atherosclerosis and the incidence of myocardial infarction [16].

Early proposal was made by Virchow, Von Rokitansky and Duguid. Virchow believed that a form of low-grade injury to the arterial wall resulted in a type of inflammatory insulation which in turn caused increased passage and accumulation of plaque constituents in the intima of artery. Rokitansky's belief subsequently elaborated upon by Duguid and was that an encrustation of small mural thrombi existed at the sites of coronary artery injury. These thrombi organized by the growth of smooth muscle cells into them and that they would become incorporated into the lesion and thus serve as sites where the lesions would progress [17].

In 1973 these two studies about atherogenesis were combined with new knowledge of the cellular and molecular biology of the arterial wall in a hypothesis termed The Response to Injury Hypothesis of atherosclerosis. A second hypothesis that was also formulated in 1973 was the Monoclonal Hypothesis which suggests that the lesion of atherosclerosis may represent some form of neoplasia [18].

Gross Pathological Changes: On gross inspection acute MI can be divided into two major types.

1. Transmural infarcts also called as Q wave infarct; in which myocardial necrosis involve the full thickness of the ventricular wall [19].

2. Subendocardial infarct also called as non Q wave infarct, in which the necrosis involves the subendocardium without extending all the way through the ventricular wall in to the epicardium.

An occlusive coronary thrombosis appears to be far more common when the infarct is transmural and localized to the distribution of a single coronary artery. Non transmural infarct frequently occur in the presence of severely narrowed but still patent coronary arteries [20].

Gross alteration of the myocardium is difficult to identify until at least 6-12 hours has elapsed following the onset of necrosis. Tissue slices of suspected infarct site are immersed in a solution of Triphenyltetrazolium chloride, which stains viable myocardium brick-red and leaves the infarcted region pale as a result of failure of uptake of vital dye by the infarct [21].

The Pathogenesis of Atherosclerosis: The term atherosclerosis is derived from Greek Athero (gruel or porridge) and Sclerosis (Hardness).

Atherosclerosis is a multifactorial process and is a principle cause of death in western civilization. It is a progressive disease process that generally begins in childhood and has clinical manifestations in middle to late adult hood. Atherosclerosis was considered to be a degenerative process because of accumulation of lipids and necrotic debris in the advanced lesions [22].

Disease of coronary artery is almost always due to atheroma and its complications particularly thrombosis. Atheroma or Atherosclerosis is patchy focal diseases of the arterial intima especially the coronary arteries which are at high risk [23].

In western countries atheromatous plagues begin to appear in the 2nd and 3rd decade of life. The earliest lesion of atherosclerosis can be found in young children and infants in the form of a lesion called the Fatty streak whereas the advanced lesion is called the fibrous plaque. Chau (2009) observed the fatty streak which consists principally of lipid-laden macrophages. It appears as an area of yellow discoloration due to large amount of lipid deposited in the foam cells.

Fatty streaks develop and circulating monocytes migrate into the tunica intima, take up oxidized low density lipoprotein (LDL) from the plasma and become lipid-laden foam cells [24]. Smooth muscle cells then migrate into and proliferate within plaque. As the lesion grows it encroaches into the lumen of the vessel and erodes the tunica media.

A mature fibrolipid plaque has a core of extracellular lipid, surrounded by smooth muscle cells and is separated from the lumen by a thick cap of collagen rich fibrous tissue. Such plaque may rupture or fissure, allowing blood to enter and compromise the lumen of the vessel and often precipitates thrombosis and local vasospasm [25].

\section{Blood Supply of Myocardium}

Myocardium is supplied by a pair of coronary arteries namely the right coronary artery and the left coronary artery. They originate at the root of aorta from the sinuses of valsalva.

\section{Left Coronary Artery}

Left coronary artery divides into two branches:

a) Anterior descending branch

b) Circumflex branch. 
It supplies major part of left atrium and left ventricular and septum between them.

\section{Right Coronary Artery}

It supplies Right atrium, interventricular septum, and both ventricles [26].

\section{Normal Coronary Blood Flow}

Resting coronary blood flow in human is approximately $225 \mathrm{ml} / \mathrm{min}$., which is about $4-5 \%$ of blood flow through coronary system $[26]$.

\section{Special Features of Cardiac Muscle Metabolism}

Under resting conditions, cardiac muscle mainly uses fatty acid for its energy. About 70\% of its normal metabolism is derived from fatty acids but under anaerobic conditions i.e. during ischaemia cardiac muscle undergoes anaerobic glycolysis for energy, producing lactic acid. In cardiac tissue accumulation of lactic acid is one of the causes of cardiac pain in ischaemic conditions. In severe ischaemia ATP in myocardial cells degrades to ADP and inorganic phosphate and ADP is further degraded to adenosine. Myocardial cell membrane is permeable to adenosine, and this causes vasodilatation of coronary arterioles during hypoxia. This adenosine may be replaced in myocardium only at the rate of two percent per hour. Hence after a serious bout of ischaemia for about a half an hour, relief of coronary ischaemia is too late, to save myocardial cells from damage leading to cellular necrosis [27].

\section{Effect of Hypoxia on Myocardial Cells}

When oxygen supply to the cell is reduced or impaired, the cell rapidly depletes its store of phosphocreatine and glycogen. ATP production falls below the level required by membrane ion pump for the maintenance of proper intracellular ionic concentrations. Due to this, osmotic balance is disrupted and cell and its membrane-enveloped organelles begin to swell. This results in over stretching of membranes leading to leak-age of cell contents chiefly enzymes. Decreased intracellular pH in anaerobic glycolysis, releases lysosomal enzymes. This lysosomal enzymes at this low $\mathrm{pH}$ cause cell damage. Rapidly respiring tissue like heart and brain are more prone to such damage $[28,29]$.

\section{Adenosine}

Adenosine monophosphate (AMP) is produced whenever the myocardial capacity to produce ATP is decreased and utilization of ATP is increased. The enzyme 5' Nucleotidase is responsible for the formation of adenosine from AMP. Adenosine is a powerful vasodilator [26].

\section{Endothelial Dysfunction \& Myocardial Ischaemia}

Endothelial vasodilator dysfunction has been implicated in the pathogenesis of coronary constriction, which is triggered by thrombosis, and the products of platelet aggregation. Lipid abnormalities, smoking, hypertension and advanced age, all of them can be associated with endothelial dysfunction [30].

In generated Eskimos the incidence of coronary heart disease is very low because they consume large amount of fish rich in Eicosapentaenoic fatty acid which decreases thromboxane there by increases prostacyclin level. This PGI2 has antiplatelet aggregation effect [31].

\section{Effects of Ischaemia in Myocardial Metabolism High Energy Phosphate Metabolism}

During the first few minutes of severe ischaemia, the production of high-energy phosphates (the sum of ATP and creatine phosphate) declines and its utilization exceeds. The combination of reduced myocardial high energy-phosphate stores, cell swelling and sarcolemmal damage appears to play a key role in cell death with ischaemia (or) reperfusion [32].

\section{Risk factors for the Development of Atherosclerosis \& Myocardial Infarction}

By risk factor it is meant, that a characteristic, which is associated with a greater than average probability, of developing coronary heart disease.

\section{Important Risk Factors for Coronary Artery Disease}

\begin{tabular}{|c|c|}
\hline Non Modifiable & Modifiable \\
\hline Age & Smoking, Obesity \\
\hline Male Sex & Hypertension Sedentary Lifestyle \\
\hline Family History & Hyperlipidemia, Diabetes Mellitus \\
\hline
\end{tabular}


Sex: Perhaps one of the best-documented risk factors for atherosclerosis is the male sex. In India, incidence of coronary artery disease in males is more common than western countries. It has been suggested that females have a decreased incidence because of protective function exerted by estrogens. Hormonal replacement therapy (HRT) reduces the risk of ischaemic heart disease in postmenopausal women [33].

Age: The incidence of Coronary artery disease increases with age. The incidence is highest in the sixth decade in Western countries. In India as per the epidemiological survey the incidence is at least a decade earlier than western countries [34].

Family History: A family history of coronary artery disease has been shown to be a strong independent risk factor for coronary artery disease.

Hyperlipidemia: In men and women between the ages of 35-44 years the serum cholesterol levels of $265 \mathrm{mg} / 100 \mathrm{ml}$ or more is associated with four times at higher risk of developing coronary artery disease than the levels below $220 \mathrm{mg} / 100 \mathrm{ml}$ of blood. Dietary saturated fatty acid elevates serum cholesterol whereas polyunsaturated fatty acid rich diet lowers the plasma cholesterol level by 10 to $20 \%$. There is a positive correlation between risk of developing ischaemic heart disease and plasma low density lipoprotein cholesterol levels $[35,36]$. It has been established that lowering the high-levels of low density lipoprotein cholesterol (LDL-C) in plasma reduces the risk of ischaemic heart disease. High plasma high density lipoprotein cholesterol (HDL-C) probably by facilitating the clearance of cholesterol from arterial smooth muscle cells and transporting it in to liver (scavenging action) reduces the risk of ischaemic heart disease [30,36] (Table 4).

\begin{tabular}{|c|c|c|}
\hline S.NO & $\mathbf{3}^{\text {rd }} \mathbf{D A Y}$ & $\mathbf{6}^{\text {th }} \mathbf{D A Y}$ \\
\hline $\mathbf{1}$ & 128 & 30 \\
\hline $\mathbf{2}$ & 76 & 25 \\
\hline $\mathbf{3}$ & 75 & 22.2 \\
\hline $\mathbf{4}$ & 56 & 26.3 \\
\hline $\mathbf{5}$ & 120 & 26.3 \\
\hline $\mathbf{6}$ & 23.76 & 84 \\
\hline $\mathbf{7}$ & 230.9 & 51.44 \\
\hline $\mathbf{8}$ & 92 & 28 \\
\hline $\mathbf{9}$ & 482.6 & 30 \\
\hline $\mathbf{1 0}$ & 165.53 & 37.53 \\
\hline $\mathbf{1 1}$ & 60.11 & 30 \\
\hline $\mathbf{1 2}$ & 94 & 28 \\
\hline $\mathbf{1 3}$ & 154 & 24 \\
\hline $\mathbf{1 4}$ & 68.18 & 26 \\
\hline $\mathbf{1 5}$ & 51.8 & 24 \\
\hline $\mathbf{1 6}$ & 122 & 25 \\
\hline $\mathbf{1 7}$ & 74 & 34 \\
\hline $\mathbf{1 8}$ & 34.82 & 25 \\
\hline $\mathbf{1 9}$ & 125.5 & 25 \\
\hline $\mathbf{2 0}$ & 136.8 & 30 \\
\hline $\mathbf{2 1}$ & 53.3 & 28 \\
\hline $\mathbf{2 2}$ & 82 & 34.12 \\
\hline $\mathbf{2 3}$ & 157 & 28 \\
\hline $\mathbf{2 4}$ & 80.6 & 26 \\
\hline $\mathbf{2 5}$ & 82.3 & 29 \\
\hline $\mathbf{S D}$ & 116.5 & 12.55 \\
\hline $\mathbf{M E A N}$ & 113.1 & 31.02 \\
\hline & & \\
\hline & 25 \\
\hline
\end{tabular}

Table 4: CK-MB levels in $3^{\text {rd }}$ and $6^{\text {th }}$ days of AMI

Hypertension: Elevated blood pressure is directly associated with atherosclerosis and increased risk of ischaemic heart disease. With blood pressure exceeding 160/95, the incidence of ischaemic heart disease is five times more common than that of normotensive individuals [37]. Diastolic pressure is more correlated with risk than systolic pressure. If diastolic pressure is more than $105 \mathrm{mmHg}$, risk of developing ischaemic heart disease is four times more when compared with individuals having diastolic pressure of $84 \mathrm{mmHg}$ or less. Hypertension if associated with other risk factors like hyperlipidemia and diabetes mellitus the individual is at higher risk of developing ischemic heart disease [38,39]. 


\title{
Clinical Diabetes Mellitus
}

A diabetic individual is two time at higher risk of developing ischaemic heart disease when compared with no-diabetic person. Insulin resistance associated with obesity, is a potent risk factor for chronic coronary heart disease. Risk is markedly increased in young diabetics. Diabetic women are more prone to ischemic heart disease than diabetic men $[40,41]$.

\section{Smoking}

Tobacco is probably the most important avoidable cause of coronary heart disease. Epidemiological studies have firmly established that cigarette smoking independently predisposes to myocardial infarction. Framingham study showed that cardiovascular mortality increased by $18 \%$ in men and 3\% in females for each 10 cigarettes smoked per day. It is both an independent risk factors for ischaemic heart disease and also interacts additively with other factors like hypertension, hyderlipidemia, and diabetic mellitus. Smoking leads to premature and more severe form of chronic disease. It is likely to develop ischaemic heart disease at younger age group. Smoking lowers, high density lipoprotein levels in males by $12 \%$ and in females by $7 \%$ [ 42 ].

Cigarette smoking is associated with high levels of carboxyhemoglobin and low oxygen delivery to tissue leading to hypoxia. Hypoxia could produce diminished lysosomal enzyme degradative ability as evidenced by impaired degradation of low density lipoprotein (LDL) by smooth muscle cells causing low density lipoprotein to accumulation in muscle cells leading to atherogenesis [43].

\section{Obesity}

Obesity predisposed to premature chronic heart disease. In the Framingham Heart study, obesity was found to be independent risk factor for cardiovascular disease in both men and women. Greater the weight, the greater is the risk particularly in younger age group. Obese individuals have higher incidence of hyperlipidemia, hyper-tension and diabetes mellitus leading to higher incidence of ischaemic heart disease [44-46].

\begin{abstract}
Alcohol
Consumption of alcohol seemed to offer some protection against coronary heart disease. However heavy alcohol consumption is associated with hypertension and increased serum cholesterol levels.
\end{abstract}

\section{Physical Activity}

Regular exercise appears to have a protective effect from coronary heart disease, by increasing the levels of high density lipoprotein levels. In sedentary individual risk of ischemic heart disease is about three times higher when compared with individual who is physically active. Physically active people have elevated levels of serum high density lipoprotein cholesterol (HDL-C) levels, which probably have beneficial effect [47].

So, HDL cholesterol is called antiatherogenic, good cholesterol and high HDL-C is having a protective role against coronary heart disease.

\section{Oral Contraceptive Drugs}

Oral contraceptive drugs may increase coronary heart disease risk.by increasing BP and by thrombogenic action.

\section{Psychosocial Factors}

Type A personalities are more prone to coronary heart disease. Coronary artery disease is of greater prevalence in upper and middle socioeconomic classes [48].

\section{Triacyglycerol (TAG)}

Pais prospective study was suggested triacylglycerol is an important risk factor. Mean triacylglycerol levels of Indians with coronary artery disease are $20-40 \mathrm{mg} / \mathrm{dl}$, lower than in Caucasians with coronary artery disease [49].

\section{HDL-C}

It is frequently called good cholesterol. Inverse relationship existed between plasma HDL-C and coronary artery disease. HDL-C levels are low in Indians with coronary artery disease. TC / HDL-C ( $>4.5)$ is considered to be the most powerful predictor of coronary artery disease. Low optimal HDL level is $>35 \mathrm{mg} / \mathrm{dl}$. NCEP defines 3 categories of HDL-C as

A) Normal HDL (35-60mg/dl) [50].

B) Low HDL $(<35 \mathrm{mg} / \mathrm{dl})$,

C) High HDL $(>60 \mathrm{mg} / \mathrm{dl})$

\section{LDL-C}

High small dense LDL-C has been found to be more specific risk factor of coronary artery disease than LDL-C. It carries three fold greater risk of coronary artery disease irrespective of LDL-C level. So, LDL cholesterol is often called as bad cholesterol [51]. 


\section{Lipoprotein(a)}

It is a low density lipoprotein like particle which has an apolipoprotein (a). It has close homology with plasminogen. Its measurements are best made in patients, when conventional risk factors are unable to help deter-mine coronary risk. Its level in patients with coronary artery disease are twice those of controls. It influences basal thrombogenic activity on endothelium [52].

\section{Serum Fibrinogen}

Fibrinogen is a major determinant of plasma viscosity and coronary artery disease risk. Frequent donation of blood, has protection against acute myocardial infarction, because it reduces blood viscosity [53].

\section{Thrombogenic Factors}

Asian Indians are known to have elevated levels of Lipoprotein (a), homocysteine, tissue plasminogen factor, Plaminogen activator factor.

\section{Homocysteinemia}

Increased plasma concentration of homocysteine doubles the risk of coronary artery disease. Excess homocysteine can form homocysteine thiolactone, a reactive intermediate which thiolate free amino acid in LDL and cause them to aggregate [54].

\section{Normal Lipprotein Meabolism}

Structure and Composition: Lipoproteins are conjugated proteins and they are molecular complexes that consists of lipids and proteins. "Lipoproteins" serve as carriers of lipids in plasma as lipids are insoluble in water. The hydrophobic cholesteryl ester and triacylglycerol form the neutral lipid core which is covered by a coat shell of amphipathic lipids like phospholipids and free cholesterol layer. This layer is interspersed by the apoproteins to make them water miscible hydrophilic complex lipoproteins $[55,56]$.

\section{Classification of Lipoproteins}

There are 3 types of classifications,

1. By Ultracentrifugation: Lipoproteins are classified by ultracentrifugation, based on, the density of lipoproteins into Chylomicrons (least dense, so float on the top of test tube), followed by VLDL, IDL, LDL and HDL (at the bottom) [57].

2. By Electrophoresis: By the migration of charged particles in electric field the lipoproteins are separated. Chylomicrons remain at the origin, followed by beta lipoproteins, then pre-beta lipoproteins and at the anode alpha lipoproteins, pre beta LP=VLDL, beta LP=LDL, alpha LP=HDL [58].

3. By apoprotein moiety: Apo B48 --- Chylomicrons, Apo B 100 --- VLDL, LDL and Apo A ---HDL.

\section{Chylomicrons}

Chylomicrons are synthesized in the intestine. They are the vehicles for the transport of exogenous triacylglycerol. Chylomicron is the largest lipoproteins in size and is the least dense. The main apoprotein in chylomicron is Apo-B48. The enzyme lipoprotein lipase located at the endothelial layer of capillaries is activated by apoC-II and released from endothelium of capillaries in to the blood stream by heparin. Lipoprotein - lipase hydrolyses the triacylglycerol present in the chylomicrons in to fatty acids and glycerol. Chylomicrons are converted to chylomicron remnants by the action of lipoprotein lipase and this chylomicron remnants have half the size of chylomicrons and are rich in cholesterol and Apo E [59].

\section{Very Low Density Lipoproteins (VLDL)}

These lipoproteins are the vehicle for the transport of endogenous triacylglycerol, from liver to extrahepatic tissues. VLDL is rich in triacylglycerol. They are synthesized in the liver from glycerol and fatty acids \& incorporated into VLDL along with hepatic cholesterol apo-B-100, ApoC \& ApoE. They pass through the space of Disse and then into hepatic sinusoids through fenestrae in the endothelial lining. When VLDL reach the peripheral tissue they are hydrolyzed by lipoprotein lipase to IDL (intermediate density lipoproteins), and, IDL is hydrolysed to LDL. The VLDL secreted into blood stream gains more apoC from HDL [60].

\section{Intermediate Density Lipoproteins (IDL)}

After hydrolysis of VLDL, short lived IDL, are formed which are partly depleted of triacylglycerol. IDL are further hydrolyzed into LDL.

\section{Low Density Lipoproteins (LDL)}

These are the major cholesterol carrying components of plasma.

Apo-B 100 is the major protein present in LDL \& comprises 25\% of LDL mass. LDL's are mainly formed from VLDL breakdown. 


\section{High Density Lipoproteins (HDL)}

HDL is synthesized from liver and intestine. Nascent HDL is discoid in shape. Lecithin cholesterol acyl transferase (LCAT) converts free cholesterol and phospholipid to cholesterol ester and lysolecithin. Apo A1 is the cofactor for LCAT. Non-polar cholesterol ester moves into hydrophobic interior of discoidal and HDL becomes spherical. HDL functions to transport cholesterol from tissues to liver, a process known as reverse cholesterol transport. This process of scavenging action of cholesterol is the main function of HDL. HDL concentration is negatively related to the incidence of coronary atherosclerosis. HDL is rich in phospholipid. These are three well defined HDL sub groups viz.HDL1.HDL2 and HDL3. The major apolipoproteins found in HDL are apo A-II, which constitutes about $90 \%$ of total HDL protein [61] (Table 5).

\begin{tabular}{|c|c|c|c|c|c|}
\hline S.NO & T-CHOL & HDL-C & TG & LDL-C & VLDL-C \\
\hline $\mathbf{1}$ & 275 & 25 & 160 & 218 & 32 \\
\hline $\mathbf{2}$ & 260 & 29 & 180 & 195 & 36 \\
\hline $\mathbf{3}$ & 286 & 32 & 164 & 221.2 & 32.8 \\
\hline $\mathbf{4}$ & 380 & 25 & 320 & 291 & 64 \\
\hline $\mathbf{5}$ & 286 & 29 & 180 & 221 & 36 \\
\hline $\mathbf{6}$ & 274 & 28 & 160 & 214 & 32 \\
\hline $\mathbf{7}$ & 314 & 28 & 200 & 246 & 40 \\
\hline $\mathbf{8}$ & 315 & 20 & 200 & 255 & 40 \\
\hline $\mathbf{9}$ & 308 & 25 & 185 & 246 & 37 \\
\hline $\mathbf{1 0}$ & 275 & 32 & 160 & 211 & 32 \\
\hline $\mathbf{1 1}$ & 288 & 37 & 164 & 218.2 & 32.8 \\
\hline $\mathbf{1 2}$ & 276 & 32 & 160 & 212 & 32 \\
\hline $\mathbf{1 3}$ & 266 & 34 & 180 & 196 & 36 \\
\hline $\mathbf{1 4}$ & 154 & 42 & 272 & 57.6 & 54.4 \\
\hline $\mathbf{1 5}$ & 300 & 25 & 150 & 245 & 30 \\
\hline $\mathbf{1 6}$ & 265 & 40 & 180 & 189 & 36 \\
\hline $\mathbf{1 7}$ & 282 & 30 & 156 & 220.8 & 31.2 \\
\hline $\mathbf{1 8}$ & 275 & 29 & 160 & 214 & 32 \\
\hline $\mathbf{1 9}$ & 326 & 33 & 188 & 255.4 & 37.6 \\
\hline $\mathbf{2 0}$ & 265 & 24 & 180 & 205 & 36 \\
\hline $\mathbf{2 1}$ & 356 & 20 & 396 & 256.8 & 79.2 \\
\hline $\mathbf{2 2}$ & 320 & 35 & 200 & 245 & 40 \\
\hline $\mathbf{2 3}$ & 300 & 25 & 150 & 245 & 30 \\
\hline $\mathbf{2 4}$ & 310 & 26 & 200 & 244 & 40 \\
\hline $\mathbf{2 5}$ & 300 & 25 & 150 & 245 & 30 \\
\hline $\mathbf{S D}$ & 55.95 & 5.69 & 57.82 & 45.39 & 22.63 \\
\hline $\mathbf{M E A N}$ & 252.4 & 28.12 & 183.8 & 205.55 & 41.48 \\
\hline & Table 5: Lipid profile in cases of AMI \\
\hline
\end{tabular}

\section{Lipoprotein Metabolism}

\section{Exogeneous Pathway}

Enterocytes absorb dietary cholesterol \& triacylglycerols from the gut in the form of free cholesterol, fatty acids and monocylglycerols. After re-esterification, cholesteryl esters \& triacylglycerols are incorporated into the core of chylomicron particles. Enterocytes synthesize apo B-48, apo A-I \& apo A-IV which together with phospholipids, from the surface layer of the chylomicrons particles. Apo B-48 is essential for chylomicron secretion [62].

The newly secreted chylomicrons pass into the intestinal lymph and gain access to the vascular system via the thoracic duct.

\section{Endogenous Pathway}

The hepatocyte is the originator and often also the acceptor of Particles involved in the endogenous pathway. The liver secretes VLDL, a triacylglycerol rich lipoprotein

LDL accounts for $70 \%$ or more of the total plasma cholesterol. The major determinant of plasma LDL concentration is the number of functional LDL receptors. The LDL receptor recognizes both apo B-100 on LDL and apo-E on remnant particles of HDL. Once 
the lipoprotein has been bound to the receptor, the receptor - lipoprotein complex localizes in the coated pit region from where it is internalized by endocytosis. The LDL receptor is recycled whilst the lipoprotein undergoes lysosomal degradation to un-esterified cholesterol and amino acids.

Myocardial infarction is said to be present if a patient exhibits two of the following three abnormalities.

1. Chest pain typical of Myocardial infarction.

2. ECG changes.

3. Elevation of Cardiac enzymes (Hurt, 1978), (the cardiac markers.)

E.C.G. Changes: 1. The earliest ECG changes are usually ST elevation. In transmural infarction Q wave begins to develop, finally T wave inversion are seen.

2. In subendocardial infarction $\mathrm{T}$ wave inversion without $\mathrm{Q}$ wave or ST elevation is noted.

Chest Pain: Retrosternal pain is the cardinal symptom of myocardial infarction, but breathlessness, sweating, vomiting and collapse or syncope are common features. Pain is more severe and lasts longer, typically present as tight-ness, heaviness or constricting in nature in the chest. Painless or silent myocardial infarction is common in elderly and diabetic patients.

\section{Enzyme Study}

Alteration in the cell permeability or necrosis or injury to tissues results in the escape of intracellular enzymes into the circulation. The measurement of these released enzymes in peripheral venous blood represents one of the sensitive techniques for detecting myocardial necrosis. The time course of depletion of an enzyme from damaged organ parallels the time course of increased activity of same enzyme in serum [63]. The serum levels of the cardiac markers i.e. CK, LDH and AST are commonly determined in the diagnosis of acute myocardial infarction (see Table 6). Isoenzymes of CK, LDH are more specific in clenching the diagnosis of myocardial infarction [64].

\begin{tabular}{|c|c|c|c|}
\hline ENZYMES & $\begin{array}{c}\text { START } \\
\text { TO RISE }\end{array}$ & $\begin{array}{c}\text { PEAK } \\
\text { EVALUATION }\end{array}$ & $\begin{array}{c}\text { DURAION } \\
\text { OF RISE }\end{array}$ \\
\hline CK & 4 to 8 hrs & 24 to 48 hrs & 3 to 5 days \\
\hline AST & 6 to 12 hrs & 24 to 48 hrs & 4 to 6 days \\
\hline LDH & 24 to 48 hrs & 72 to 146 hrs & 8 to 14 days \\
\hline \multicolumn{4}{|c}{}
\end{tabular}

\section{Enzymes}

\section{Creative Kinase (E.C.2.7.3.2)}

It was formerly called as Creatine Phosphokinase (CPK).

Its systemic name is Adenosine triphosphate, creatine phosphotransferase (CK). Phosphocreatine is the most important storage form of high energy phosphate in muscles. The enzyme creatine kinase catalyses the reversible phosphorylation of creatine by ATP. Optimum $\mathrm{pH}$ for forward reaction is 9 and for backward reaction are 6.7. Hence equilibrium position for this reaction is dependent on $\mathrm{pH}$. At neutral $\mathrm{pH}$ creatine phosphate has a much higher phosphorylating potential than ATP and this favours the reverse reaction i.e. formation of ATP from creatine phosphate by transferring high energy phosphate group to ADP to form ATP using creatine phosphate as phosphate donor. This reaction is called "Lohmann's" reaction [65].

$$
\begin{gathered}
\text { Creatine + ATP <-----CK pH9----- }>\text { ADP + Creatine phosphate } \\
\mathrm{Mg}^{+2}
\end{gathered}
$$

The reverse reaction proceeds two to six times faster-than the forward reaction, depending on the reaction conditions. Magnesium is an obligate activating ion to form ADP and ATP- Mg complex. The enzyme CK in serum is unstable. Activity is restored by $\mathrm{N}$-acetyl cysteine. When muscle contracts ATP is consumed and CK catalyses the re-phosphorylation of ADP to form ATP using creatine phosphate as the phosphorylation reservoir [66].

Creatine kinase is a dimer composed of two polypeptides, consisting of two subunits each with a molecular weight of about 40,000 . These subunits are named as B for brain, $\mathrm{M}$ for muscle. CK exists in three different pairs of subunits forming three isoenzymes[67]. (a) BB-CK-1 (b) MB-CK-2 (c) MM-CK-3. Out of these three isoenzymes, CKMB is predominant in myocardium and the elevated $\mathrm{CKMB}$ levels are more specific for the diagnosis of myocardial infarction [68]. Each of CK isoenzymes shows a characteristic electrophoretic mobility. Increase in CK level excludes liver disease. Isoenzyme originating from muscle is far more in quantity. So, detection of CKMB isoenzyme is important in the diagnosis of myocardial infarction. CKMB is $15-24 \%$ of the total CK in myocardial infarction.

$\%$ relative index $===\mathrm{CKMB}$ mass ${ }^{*} 100$ total CK activity

$\%$ Relative index aids in the interpretation of $\mathrm{CKMB}$ concentration for the detection of acute myocardial infarction and in 
differentiating cardiac enzyme release from skeletal muscle release.

Normal value of CKMB is $0-5 \mathrm{U} / \mathrm{L}$.

Clinical significance: Following myocardial infarction CKMB activity rises along with total CK activity. CKMB activity begins to rise within 4 to 6 hours and reaches peak by 12 to 24 hours after onset of chest pain and reaches normal level by 48 hours [69]. The peak level of activity depends on size and extent of infarction. Therefore, CK estimation is very useful and sensitive indicator to detect early cases where ECG changes are ambiguous.

Other Conditions Causing Elevation of Creatine Kinase Activity in Serum: The level of CK is very much elevated in all types of muscular dystrophies especially Duchenne's type. CPK is elevated in crush injury, in intramuscular injection, hypothyroidism, delirium tremors, in women following delivery, after severe exercise, seizures, polymyositis, malignant hyperthermia, acute rhabdomyolysis, and paroxysmal myoglobinuria (Table 7). Hence diagnosis of myocardial infarction should be based on both clinical findings and biochemical parameters. The CK levels are not increased in hemolysis or in congestive cardiac failure and therefore CK has an advance over LDH.

Lactate Dehydrogenase (e.c.1.1.127): LDH is the enzyme of glycolysis. Its systemic name is L-Lactate-NAD+ Oxidoreductase (LDH). LDH (Zinc-protein complexes) is a hydrogen transfer enzyme which catalyses the oxidation of $\mathrm{L}-\mathrm{Lactate}$ to Pyruvate with mediation of $\mathrm{NAD}^{+}$as hydrogen acceptor. LDH playing an important part in anaerobic glycolysis. This is a reversible reaction and reaction equilibrium strongly favours reverse reaction viz. The reduction of Pyruvate to lactate. Enzyme is located in the cytoplasm [70].

Lactate + NAD $^{+}<----$LDH----> Pyruvate + NADH $+\mathrm{H}^{+}$
\begin{tabular}{|cc|c|cc|}
\hline CHAIN & MOBILITY & \multicolumn{2}{|c|}{ OF ORIGIN } \\
\hline CK-1 & BB & MAXIMUM & BRAIN & $01 \%$ \\
\hline CK-2 & MB & INTERMEDIATE & HEART & $09 \%$ \\
\hline CK-3 & MM & LEAST & SKELETAL & - \\
\hline
\end{tabular}
Table 7: Type polypeptide electrophoretic tissue percentage in blood

LDH does not act on D-lactate. The equilibrium is such that the backward reaction above is more than twice as fast as forward and most workers have used Pyruvate as substrate. Lactate has the advantage of being more stable than Pyruvate and NAD+ is cheaper than $\mathrm{NADH}$. At $\mathrm{pH} 7$ the equilibrium of reaction is to the right. At $\mathrm{pH} 8$ or 9 reverse reaction occurs i.e. from right to left.

Lactate dehydrogenase enzyme LDH is a tetramer and has a molecular weight of 1,34,000 and is composed of four poly-peptide chains and is composed of two different type $\mathrm{M}$ and $\mathrm{H}$ subunit (MW of each is about 34,000) [71]. Only the tetrameric molecule possesses the catalytic activity. In the order of decreasing anodal mobility in alkaline medium (in electrophoresis), are LDH1, LDH2, LDH3, LDH4 and LDH5 (Table 8). Moving fastest towards the anode is designated as LDH-1. Slowest moving isoenzyme is called LDH-5. Hence these protomers combine in the following ways to form five isoenzymes.

\begin{tabular}{|c|c|c|c|c|c|}
\hline 1. & LDH & $($ H H H H $)$ & H4. & Heart and RBC & $25-45 \%$ \\
\hline 3. & LDH3 & (H H M M $)$ & H2 M2. & Pancreas, brain & $20-40 \%$ \\
\hline 2. & LDH2 & (H H H M $)$ & H3 M. & Heart and RBC, Kidney & $10-25 \%$ \\
\hline 4. & LDH4 & (H M M M $)$ & H M3. & Liver, skeletal muscle & $0-12 \%$ \\
\hline 5. & LDH5 & ( M M M M $)$ & M4. & Skeletal muscle and liver & $0-12 \%$ \\
\hline \multicolumn{5}{|c|}{ Table 8: Isoenzyme subunit site percentage } \\
\hline
\end{tabular}

LDH-1 moves just behind the tearing edge of the albumin fraction. LDH-5 migrates with the gammaglobulin. The difference in electrophoretic mobility is due to different electric charges on the isoenzyme produced by the difference in the contents of acidic and basic aminoacids. The isoenzymes have different $\mathrm{pH}$ optima and $\mathrm{Km}$ value. $\mathrm{Km}$ for LDH-1 is high. Km for LDH-5 is low. Normally LDH-1 is $16-28 \%$ of total LDH. LDH-2 is 29-37\% of total LDH LDH > 1500 U/L is associated with grave prognosis.

Distribution of Isoenzymes in Human Tissue: LDH is not a tissue specific enzyme. LDH-1, LDH-2 are predominant in myocardium, erythrocyte, Kidney. LDH-4, LDH-5 are predominant in liver and skeletal muscle. LDH-3, LDH-4 are present in lung, spleen, and endocrine glands, and lymph nodes [72]. LDH-1 and LDH-2 are predominant after myocardial infarction. LDH4 and LDH-5 are predominant in acute viral hepatitis.

Clinical Significance: In myocardial infarction LDH levels begins to raise 12 to 18 hours after onset of chest pain, reaches peak by 48 to $72 \mathrm{hrs}$ after episode and falls back to normally by 10 to 12 days $[30,73,69]$. Because of its prolonged half-life LDH-1 is a clinically sensitive (90\%) marker for myocardial infarction when used after 24 hours of MI attack. In heart LDH is inhibited by pyruvate, so pyruvate cannot form lactate. Optimum interval for analysis for LDH isoenzyme is 48-72 hours period after the onset of chest pain. In normal healthy individual LDH-2 is more than LDH-1 in serum but in myocardial infarction LDH-1 isoenzyme increased more than LDH2 isoenzyme so there is reversal of ratio this is called flipped pattern (LDH-1/LDH-2 $>1$ in MI after 
12-24 hours and the ratio remains $>1$ for seven days) which is present in more-than $80 \%$ of patients with myocardial infarction [74]. Diagnostic sensitivity of LDH estimation of myocardial infarction is around 90\% and diagnostic specificity is $90-99 \%$ [75]. Favorable response to therapy may be accompanied by fall in serum LDH enzyme and recurrence by rise in LDH. LDH-1 rises with in ten to twelve hours of myocardial infarction, peak values attained at 72-144 hours and return to normal in ten days, paralleling total LDH. While taking blood for LDH estimation, hemolysis is avoided as LDH level is 100-150times more inside the $\mathrm{RBC}$ than in plasma, so giving a false positive test [76].

Other Causes of Elevation of LDH Activity: Total LDH values are also moderately elevated in myocarditis, hepatic congestion with cardiac failure, and leukemia, sever shock, in pernicious anemia, anoxia, haemolysis. High values can occur in primary or secondary tumors of the liver and very high values are seen in liver necrosis following exposure to carbon tetrachloride. High values are also seen in megaloblastic and haemolytic anemic, in renal disease and in generalized carcinomatosis, Hodgkin's disease, lung cancer, germ cell tumours. Increase in CSF LDH activity has been reported in the presence of tumor of CNS.

Isoenzymes: Isoenzymes or isozymes are the multiple forms of an enzyme catalyzing the same reaction. Isoenzymes are physically distinct forms of the same enzyme. They thus catalyses the same chemical reaction, but differ from each other structurally, electrophoretically, immunologically, in catalytic activity. Synthesis of each is under its own genetic control. The pattern of isoenzymes found in the plasma may serve as a way of identifying the site of tissue damage e.g. Creatine kinase and LDH are often used in the diagnosis of myocardial infarction.

Lactate dehydrogenase (LDH) isoenzymes differ from one another at the level of the quaternary structure. The re-action proceeds at a measurable rate only in the presence of enzyme catalyst $\mathrm{LDH}$.

Cardiac muscle is richest in LDH-1 and LDH-2. In myocardial infarction total LDH activity is increased while H4 activity isoenzyme is increased 5 to 10 times more (Table 9). The magnitude of the peak value as well as the area under the graph will be roughly proportional to the size of the myocardial infarct. Therefore, study of isoenzymes of LDH is of greater importance in differential diagnosis. Spleen, lung, pancreas, lymph nodes, adrenal, leukocytes and thyroid are richest in LDH-3 and Kidney richest in LDH-2.

\begin{tabular}{|c|c|c|}
\hline S.NO & $\mathbf{3}^{\text {rd }} \mathbf{D A Y}$ & $\mathbf{6}^{\text {th }} \mathbf{D A Y}$ \\
\hline $\mathbf{1}$ & 618.4 & 428 \\
\hline $\mathbf{2}$ & 620 & 480 \\
\hline $\mathbf{3}$ & 678.1 & 478 \\
\hline $\mathbf{4}$ & 975 & 625.4 \\
\hline $\mathbf{5}$ & 585 & 530 \\
\hline $\mathbf{6}$ & 1853 & 1509 \\
\hline $\mathbf{7}$ & 1544 & 1041 \\
\hline $\mathbf{8}$ & 720 & 600 \\
\hline $\mathbf{9}$ & 1874 & 1574 \\
\hline $\mathbf{1 0}$ & 800 & 585 \\
\hline $\mathbf{1 1}$ & 1127 & 780 \\
\hline $\mathbf{1 2}$ & 526 & 400 \\
\hline $\mathbf{1 3}$ & 1240 & 925 \\
\hline $\mathbf{1 4}$ & 520 & 450 \\
\hline $\mathbf{1 5}$ & 480.9 & 380 \\
\hline $\mathbf{1 6}$ & 422 & 400 \\
\hline $\mathbf{1 7}$ & 378 & 325 \\
\hline $\mathbf{1 8}$ & 938.8 & 570.6 \\
\hline $\mathbf{1 9}$ & 546 & 440 \\
\hline $\mathbf{2 0}$ & 752.6 & 620 \\
\hline $\mathbf{2 1}$ & 669 & 440 \\
\hline $\mathbf{2 2}$ & 1116 & 500 \\
\hline $\mathbf{2 3}$ & 543 & 420 \\
\hline $\mathbf{2 4}$ & 885.4 & 500 \\
\hline $\mathbf{2 5}$ & 418 & 302 \\
\hline $\mathbf{S D}$ & 421.42 & 326.53 \\
\hline $\mathbf{M E A N}$ & 833.2 & 612.12 \\
\hline & & \\
\hline $\mathbf{1 0}$ & \\
\hline
\end{tabular}

Table 9: Serial serum enzyme estimations of LDH in patients with AMI 
$\mathrm{LDH}$ - X has been found between LDH-3 and LDH-4 in mature Testis and in spermatogenesis. Tumors are richest in LDH-3, LDH-4, LDH-5. LDH-1 is associated with oxidative metabolism and LD5 with anaerobic glycolysis [77].

\section{Distinguishing these Isoenzymes}

Heat stability: LDH-1 has been shown to be more heat resist-ant.

Heat stability index: The ratio of the activity after heating at $600 \mathrm{C}$ for an hour to that of untreated serum.

Behavior towards inhibitors: Inhibition of serum LDH by potassium oxalate and urea [78].

\section{Serum Alpha Hydroxybutyrate}

Dehydrogenase: LD catalyses reversible reduction of other Alpha Keto acid besides Pyrucate. Alpha KetoButyrate dehydrogenase $=56-125 \mathrm{U} / \mathrm{L}$ at $25^{\circ} \mathrm{C}$.
$\mathrm{LD} / \mathrm{HBD}$
1.18 - 1.6 normally
$\mathrm{LD} / \mathrm{HBD}$
$<1.18$ Myocardial infarction

Alpha HBD activity is a more sensitive index of myocardial infarction, than LDH and frequently elevated for a long time.

Aspartate Aminotransferase (A.S.T) (E.C.2.6.1.1): Formerly called serum glutamate oxaloacetate transaminase (SGOT). The systemic name is Aspartate oxoglutarate amino transferase (AST). Aminotransferases are enzymes, which catalyses the transfer of amino groups from alpha amino acids to a ketoacid to form the new amino acid and new ketoacid. Transamination reactions are reversible reactions. Pyridoxal 5-phosphate is a versatile coenzyme that participate in transamination reaction. Pyridoxal 5 -phosphate produce a marked increase in enzyme activity. Since oxaloacetate cannot pass through the inner membrane, it is converted by transamination to Aspartate that can move across the membrane. The two aminotransferase enzymes are

1. A.S.T --- Aspartate Aminotransferase.

2. A.L.T ---- Alanine Aminotransferase.

Aspartate aminotransferase (AST): The term transaminase is accepted as an alternative to amino transferase by the Enzyme Commission. It is predominantly present in myocardium and its levels are high in serum when there is myocardial damage due to infarction. Aspartate aminotransferase catalyses transfer of amino group from L-aspartate to alpha ketoglutarate producing Oxaloacetate and L- glutamate.

$$
\begin{aligned}
& \text { Aspartate + alpha ketoglutarate <--------AST--------> Oxaloacetate + L glutamate. } \\
& \text { P-5-P }
\end{aligned}
$$

The reaction is reversible and equilibrium favours formation of Aspartate. AST is found both in cytosol and mitochondria.

Distribution in Human Tissues: AST is widely distributed in animal tissue. Aspartate aminotransferase is present in human plasma, bile, CSF and saliva but not in urine.

Clinical Significance: In acute myocardial infarction serum levels of AST are found to be increased. On the average serum levels starts to rise 6 to 8 hours after onset of infarction and peak values are reached after 18 to 24 hours and values fall to normal range by 4 th or 5 th day provided no new infarct has occurred $[25,59,61,62]$.

Abnormal aspartate aminotransferase levels are observed in more than $97 \%$ of cases of myocardial infarction when correctly timed blood specimens are analyzed. Average increases are 4 to 5 times the upper limit of normal are observed. Alanine aminotransferase (ALT) are normal in myocardial infarction. Peak value of aspartate aminotransferase activity is roughly proportional to the extent of damage [69]. AST content in myocardial cells is 10,000 times and in liver cells 5,000 times more than the serum value. Therefore AST level in serum is highly elevated in myocardial infarction and mildly elevated in liver disease. AST more than 350U/L is fatal, whereas AST $>150 \mathrm{U} / \mathrm{L}$ is associated with high mortality whereas AST <50 U/L is associated with low mortality [60].

\section{Summary}

Myocardial infarction is now becoming more common in our country. Hence it has become important to achieve early diagnosis in these patients to assess the effectiveness of treatment which is being given. This is achieved by serial estimations of Enzymes in patients Serum.

This study is done in patients who came to hospital within 1-2 hours after onset of chest pain and diagnosed as acute myocardial infarction with help of E.C.G. findings.

In the present study 20 cases of normal subjects and 25 cases of myocardial infarction cases are compared and found that the CK \& CK-MB were increased in the 1 st day of attack and their decrease was noticed on $3^{\text {rd }}$ day. This shows that the estimation of CK \& $\mathrm{CK}-\mathrm{MB}$ are the earliest diagnostic tools for the diagnosis of myocardial infarction.

The estimation of total LDH, LDH-1 and LDH-2 were made and noticed that the total LDH and LDH-1 and LDH-2 showed peak levels starting from $3^{\text {rd }}$ day to $6^{\text {th }}$ day of the myocardial infarction attacks. This study confirms the diagnostic and therapeutic 
evaluation of the myocardial infarction cases.

The estimations of AST in 25 disease cases of myocardial infarction are done and the elevation of this enzyme is noticed from the $3^{\text {rd }}$ day onwards and its decline was noticed on $6^{\text {th }}$ day. This enzyme estimation will clearly indicate the progress of the myocardial infarction cases.

In $80 \%$ of the myocardial infarction cases the lipoprotein pattern increase is noticed. This clearly shows that total lipoprotein are the predisposing factors for the myocardial infarction.

Especially LDL is markedly increased in acute cases of myocardial infarction. HDL decrease is also noticed in 50 to $75 \%$ of myocardial infarction cases (Table 10).

\begin{tabular}{|c|c|c|c|c|}
\hline S.NO & INVESTIGATION & VALUES & CONTROLS & MI \\
\hline & & & SUBJECTS & SUBJECTS \\
\hline 1 & Total cholesterol & Mean & 206 & 252.4 \\
\hline & & SD & 34.8 & 55.95 \\
\hline 2 & Triacylglycerol & Mean & 131.6 & 183.8 \\
\hline & & SD & 17.49 & 57.85 \\
\hline 3 & HDL cholesterol & Mean & 50.7 & 28.12 \\
\hline 4 & & SD & 15.43 & 5.69 \\
\hline & LDL cholesterol & Mean & 130.73 & 205.55 \\
\hline 5 & VLDL cholesterol & Mean & 26.32 & 41.48 \\
\hline & & SD & 3.5 & 22.63 \\
\hline
\end{tabular}

Table 10: Comparative statistical analysis of the enzyme / Estimations in AMI patients and in controls

In $80 \%$ of the acute myocardial infarction cases the increase of total serum cholesterol level was noticed. This estimation also shows that cholesterol is also one of the risk factor for myocardial infarction.

Myocardial infarction has become a major public health problem all over the word. The enzyme estimation of greatest change depends on the time interval after the suspected infarct. Enzyme elevations are present in about 95\% cases of myocardial infarction and may reach very high level. A second rise in enzyme level after their return to normal indicate extension of infarction or development coronary heart failure, when CK do not rise. Rate of appearance of an enzyme in the circulation appear to depend on the rate and reperfusion of damaged myocardium and on size of enzyme molecule. Magnitude of peak value will be roughly proportional to the size of myocardial infarction. Study of isoenzyme LDH is of greatest importance in differential diagnosis. CK-MB values are very useful to detect early cases. Peak values of AST are roughly proportional to the extent of cardiac damage.

The extent of elevation to total CK and CK-MB on the 1st day of attack will indicate the severity of the attack. Serum total LDH and LDH-1 and LDH-2 levels are elevated from the 3rd day onwards. Normally LDH-2 is more than LDH-1 where as in cases of myocardial infarction LDH1 increase is clearly seen from our cases. These alteration of isoenzymes is called flipped pattern. These pattern is clearly seen in cases of myocardial infarction.

Sharp rise of AST was noticed from $3^{\text {rd }}$ day onwards and decrease is seen $6^{\text {th }}$ day. The elevated values of AST on $3^{\text {rd }}$ day will indicate the attack of myocardial infarction.

Hypercholesterolemia is noticed in $90 \%$ of cases of myocardial infarction. Hypertriacylglyceridemia is also noted. There is a rise of LDL cholesterol in all the cases of myocardial infarction, whereas HDL-C levels are decreased in all the cases of myocardial infarction. So, the elevation of total cholesterol levels, Triacylglycerol, LDL-cholesterol, VLDL- cholesterol are the important risk factors for the attack of myocardial infarction.

Hence, we conclude that the serial estimations of serum enzymes like total CK, CK-MB, total LDH, LDH-1, LDH-2 and serum AST are increased in myocardial infarction cases and also helpful in achieving diagnosis, in the assessment of therapy being given and to predict the prognosis of acute myocardial infarction cases.

\section{Acknowledgements}

It gives me great pleasure to take this opportunity to thank everyone who have helped me during the course of my study and preparing the dissertation. It gives me immense pleasure to express my deep sense of gratitude and sincere thanks to Dr. M. Siva Reddy, MD., Professor and HOD of Biochemistry, for all his guidance, inspiration, moral support and encouragement throughout my post graduate course of dissertation.

I am highly indebted to Dr. U. Jaya Rami Reddy, MD., Professor of Biochemistry for his able guidance, encouragement and 
constructive criticism during the course of my study and during the preparation of this dissertation.

I wish to express my sincere thanks to Dr. KS. Thirumala Chari, MD., Principal, Kurnool Medical College, Kurnool for giving me this opportunity and also for being constant source of inspiration.

I would like to thank Dr. Sudha Kar, MD., Assistant professor of Biochemistry for valuable suggestions, encouragement and guidance during the course of study and the preparation of dissertation.

I owe a lot to Dr. T. Rama Krishna Reddy, M.D., (D.M) retired Principal, Professor and HOD of Cardiology for constant encouragement, support and valuable guidance and for his cooperation during this study.

I thank Dr. P. Chandra Sekhar, MD, DM., Assistant professor of Cardiology for his cooperation during this study.

I extend my thanks to Dr. Rama Mani, MD, tutor in Biochemistry for her valuable guidance and encouragement. My thanks to all my friends and colleagues for their cooperation and to all those patients who were part of the study.

I thank all the staff members of the department for their cooperation during my study.

\section{References}

1. Sennett SM, Pollock ML, Pels AE, Foster C, Dolatowski R, et al. (1987) Medical Problems of Patients in an Outpatient Cardiac Rehabilitation Program. J Cardiopulmonary Rehabilitation 7: 458-65.

2. Litvack F, Grundfest WS, Lee ME, Carroll RM, Foran R, et al. (1985) Angioscopic visualization of blood vessel interior in animals and humans. Clinical Cardiolo 8: 65-70.

3. Chau AH (2009) Development of an intracoronary Raman spectroscopy (Doctoral dissertation, Massachusetts Institute of Technology).

4. Stary HC, Chandler AB, Dinsmore RE, Fuster V, Glagov S, et al. (1995) A definition of advanced types of atherosclerotic lesions and a histological classification of atherosclerosis. A report from the Committee on Vascular Lesions of the Council on Arteriosclerosis, American Heart Association. Circulation 92: 1355-74.

5. Apple F, Preese L, Bennett R, Fredrickson A (1988) Clinical and analytical evaluation of two immunoassays for direct measurement of creatine kinase MB with monoclonal anti-CK-MB antibodies. Clin Chem 34: 2364-7.

6. Armstrong A, Duncan B, Oliver MF, Julian DG, Donald KW, et al. (1972) Natural history of acute coronary heart attacks. A community study. Br Heart J $34: 67$. 7. Abbott RD, Wilson PW, Kannel WB, Castelli WP (1988) High density lipoprotein cholesterol, total cholesterol screening, and myocardial infarction. The Framingham Study. Arteriosclerosis 8: 207-11.

8. AHA committee report (1986) Risk factors and coronary disease. Circulation 62: 449-54.

9. Auerbach O, Hammond EC, Garfinkel L (1965) Smoking in relation to Atherosclerosis of the Coronary Arteries. New England J Med 273: 775-9.

10. Berne RM (1980) The role of adenosine in the regulation of coronary blood flow. Circ Res 47: 807-13.

11. Brezenka V, Padmos I (1994) Coronary heart disease risk factor in women. Eur. Heart J. 15:1571-84.

12. Collinson PO, Rosalki SB, Flather M, Wolman R, Evans T (1988) Early diagnosis of myocardial infarction by timed sequential enzyme measurements. Ann Clin Biochem 25: 376-82.

13. Begmeyer HW (1965) Methods of Enzymatic analysis. Verlog Chemie Ed 2.

14. Clinical laboratory methods by John D Bauer: 9th edition.

15. Carlson CA, Böttiger LE (1972) Ischæmic Heart-Disease in Relation to Fasting Values of Plasma Triglycerides and Cholesterol. The Lancet 299: 865-8.

16. Clarke R, Daly L, Robinson K, Naughten E, Cahalane S, et al. (1991) Hyperhomocysteinemia: an independent risk factor for vascular disease. N Engl J Med 324: 1149-55.

17. Durguid JB (1946) Thrombosis as a factor in the pathogenesis of coronary atherosclerosis. J Pathol Bacteriol 58: 207-12.

18. Neumeier D, Prellwitz W, Würzburg U, Brundobler M, Olbermann M, et al. (1976) Determination of creatine kinase isoenzyme MB activity in serum using immunological inhibition of creatine kinase M subunit activity. Activity kinetics and diagnostic significance in myocardial infarction. Clin Chim Acta 73: 445-51.

19. Christopher R W edwards (1996) Davidsons- Principles and practice of medicine, 17th edition.

20. Devlin TM (2010) Text book of Biochemistry with clinical correlations, 4th edition, 1997.

21. Epstein FH: Precocious heart disease Symposium, V world congress of cardiology, New Delhi, 1966.

22. Faggiotto A, Ross R, Harker L (1984) Studies of hypercholesterolemia in the nonhuman primate. I. Changes that lead to fatty streak formation. Arteriosclerosis 4: $323-40$.

23. Faggiotto A, Ross R (1984) Studies of hypercholesterolemia in the nonhuman primate. II. Fatty streak conversion to fibrous plaque. Arteriosclerosis 4: $341-56$.

24. Gordon T, Kannel WB (1968) The Framingham study: an epidemiological investigation of cardiovascular disease. US Department of Health, Education, and Welfare, National Institutes of Health.

25. Gerhardt W, Waldenström J, Hörder M, Hofvendahl S, Billström R, et al. (1982) Creatine kinase and creatine kinase B-subunit activity in serum in cases of suspected myocardial infarction. Clin Chem 28: 277-83.

26. Guyton AC, Text book of medical physiological, 8th edition.

27. Gamal R, Swain DG, Nightingale PG, Buckley BM (1990) The effective use of cardiac enzymes and electrocardiograms in the diagnosis of acute myocardial infarction in the elderly. Postgrad Med J 66: 375-7.

28. Voet, D, \& Voet, JG (2011). Biochemistry (4th ed.). Hoboken, NJ: Wiley.

29. Glueck CJ, Mattson F, Bierman EL (1978) Sounding Board. Diet and coronary heart disease: another view. N Engl J Med 298: 1471-3.

30. Hurst J Wills (1978) The Heart, Arteries and veins, 4th ed

31. Henry RT (1960) American Journal of Clinical Pathology 34. 
32. Murray R, Mayes PA, Rodwell, VW, Granner DK (2000) Harper's Biochemistry 25th (edn). New York, NY: Appleton \& Lange.

33. Harrison's Principles of internal Medicine-12th (edn).

34. Jørgensen PJ, Hørder M, Selmer J, Bøtker HE (1990) Analytical evaluation of a sensitive enzyme immunoassay for determinations of creatine kinase isoenzyme MB. Clin Chem 36: 1502-5.

35. Jensen AE, Reikvam Å, Åsberg A (1990) Diagnostic efficiency of lactate dehydrogenase isoenzymes in serum after acute myocardial infarction. Scand J Clin Lab Invest 50: 285-9.

36. Kannel WB, McGee D, Gordon T (1976) A general cardiovascular risk profile: the Framingham Study. Am J Cardiol 38: 46-51.

37. Littman AB (1993) Review of psychosomatic aspects of cardiovascular disease. Psychother Psychosom 60: 148-67.

38. Lung (1974) American Journal of Clinical Pathology 67.

39. Pick R, Johnson PJ, Glick G (1974) Deleterious effects of hypertension on the development of aortic and coronary atherosclerosis in stumptail macaques (Macaca speciosa) on an atherogenic diet. Circulation Res 35: 472-82.

40. Ladi RN, Hollaar L, Souverijn JH, van der Laarse A (1990) Quantitation of cumulative release of lactate dehydrogenase isoenzyme-1 in plasma of patients with acute myocardial infarction using a commercially available test. Clin Physiol Biochem 8: 250-5.

41. Gordon T, Castelli WP, Hjortland MC, Kannel WB, Dawber TR (1977) High density lipoprotein as a protective factor against coronary heart disease: the Framingham Study. The American J of Med 62: 707-14.

42. McComb JM, McMaster EA, MacKenzie G, Adgey AA (1984) Myoglobin and creatine kinase in acute myocardial infarction. Br Heart J 51: $189-94$.

43. Paniagua J, Muñoz AM, Tuset N, Gras J (1984) Study of Lipids (Cholesterol, Triglycerides and Phospholipids), Plasma Lipoproteins (HDL-cholesterol) and Apoproteins (Apo a and Apo B in Patients With Acute Myocardial Infarction. Med Clin (Barc) 93: 134-8.

44. Meade TW, Ruddock V, Stirling Y, Chakrabarti R, Miller GJ (1993) Fibrinolytic activity, clotting factors, and long-term incidence of ischaemic heart disease in the Northwick Park Heart Study. The Lancet 342: 1076-9.

45. Ashley FW, Kannel WB (1974) Relation of weight change to changes in atherogenic traits: the Framingham Study. J Chronic Diseases 27: 103-14.

46. Keys A, Fidanza F, Karvonen MJ, Kimura N, Taylor HL (1972) Indices of relative weight and obesity. J Chronic Dis 25: $329-43$.

47. Suchita P Dandekar (2009) Medical Biochemistry, 1st (edn).

48. Masuda J, Ross R (1990) Atherogenesis during low level hypercholesterolemia in the nonhuman primate. I. Fatty streak formation. Arteriosclerosis 10: 164-77.

49. Ogston D, Bennett NB, Ogston CM (1970) The influence of cigarette smoking on the plasma fibrinogen concentration. Atherosclerosis 11: 349-52.

50. MacMahon S, Peto R, Cutler J, Collins R, Sorlie P, et al. (1990) Blood pressure, stroke, and coronary heart disease. Part 1, Prolonged differences in blood pressure: prospective observational studies corrected for the regression dilution bias. Lancet 335: 765-74.

51. Powell KE, Thompson PD, Caspersen CJ, Kendrick JS (1987) Physical activity and the incidence of coronary heart disease. Annu Rev Public Health 8: 253-87.

52. Pohorecky LA (1990) Interaction of alcohol and stress at the cardiovascular level. Alcohol 7: 537-46.

53. Pasternac RC (1965) Acute myocardial infarction. Clin Pathol 38: 231-6.

54. Ross R, Glomset JA (1976) The pathogenesis of atherosclerosis (first of two parts). N Engl J Med 295: 369-77.

55. Ross R (1993) The pathogenesis of atherosclerosis: a perspective for the 1990s. Nature 362: 801-9.

56. Olson RE (1998) Discovery of the lipoproteins, their role in fat transport and their significance as risk factors. J Nutr 128: 439S-43S.

57. Rotenberg Z, Davidson E, Weinberger I, Fuchs J, Sperling O, et al. (1988) The efficiency of lactate dehydrogenase isoenzyme determination for the diagnosis of acute myocardial infarction. Arch Pathol Lab Med 112: 895-7.

58. Robins pathological basis of diseases- $3^{\text {rd }}(\mathrm{edn}), 2015$.

59. Stary HC, Chandler AB, Glagov S, Guyton JR, Insull W, et al. (1994) A definition of initial, fatty streak, and intermediate lesions of atherosclerosis. A report from the Committee on Vascular Lesions of the Council on Arteriosclerosis, American Heart Association. Circulation 89: $2462-78$.

60. Steenland K (1992) Passive smoking and the risk of heart disease. JAMA 267: 94-9.

61. Shea S, Ottman R, Gabrieli C, Stein Z, Nichols A (1984) Family history as an independent risk factor for coronary artery disease. J Am Coll Cardiol 4: 793-801.

62. Searcy RL (1969) Diagnostic Biochemistry. MaGraw-Hill, New York.

63. Zilva Joan F (1988) Clinical chemistry in diagnosis and treatment.

64. Tenanant R (1935) Effect of coronary occlusion on MI. A M J Physiol 112: 351.

65. Tietz W, Carl A Burtis, Edward R Ashwood (1994) Text book of clinical chemistry, $2^{\text {nd }}$ edn.

66. Virchow R (1856) Phalogose undethrombose is gefos system. 0458.

67. Galen RS, Reiffel JA, Gambino SR (1975) Diagnosis of acute myocardial infraction: Relative efficiency of serum enzyme and isoenzyme measurements. JAMA 232: $145-7$.

68. Boone DJ, Tietz NW, Weinstock A (1977) Significance of gamma-glutamyl transferase (GGT) activity measurements in alcohol-induced hepatic injury. Ann Clin Lab Sci 7: 25-8.

69. Grande P, Christiansen C, Pedersen ASGER, Christensen MS (1980) Optimal diagnosis in acute myocardial infarction. A cost-effectiveness study. Circulation 61: 723-8.

70. Meister A (1950) Reduction of $\alpha, \gamma$-diketo and $\alpha$-keto acids catalyzed by muscle preparations and by crystalline lactic dehydrogenase. J Biol Chem 184: 117-30.

71. Wacker W, Ulmer D, Valle B (1956) Fundamentals of clinical chemistry. N Eng J Med 255: 449.

72. Hammond GL, Nadal-Ginard B, Talner NS, Markert CL (1976) Myocardial LDH isozyme distribution in the ischemic and hypoxic heart. Circulation 53: 637-

43.

73. Fowler N (1976) Coronary artery disease: myocardial infarction and coronary artery aneurysm. In Cardiac Diagnosis and Treatment. Harper \& Row, New York. 74. Vasudevan Text book of Biochemistry, 2nd edn.

75. Bruns DE, Emerson JC, Intemann S, Bertholf R, Hill KE, et al. (1981) Lactate dehydrogenase isoenzyme-1: changes during the first day after acute myocardial infarction. Clin Chem 27: 1821-3. 
76. Harold Varley (1980) Practical clinical Biochemistry $5^{\text {th }}$ edn.

77. Tunstall-Pedoe H, Kuulasmaa K, Amouyel P, Arveiler D, Rajakangas AM, et al. (1994) Myocardial infarction and coronary deaths in the World Health Organization MONICA Project. Registration procedures, event rates, and case-fatality rates in 38 populations from 21 countries in four continents. Circulation 90: 583-612. 78. Mohanty I, Arya DS, Dinda A, Talwar KK, Joshi S, et al. (2004) Mechanisms of cardioprotective effect of Withania somnifera in experimentally induced myocardial infarction. Basic Clin Pharmacol Toxicol 94: 184-90.

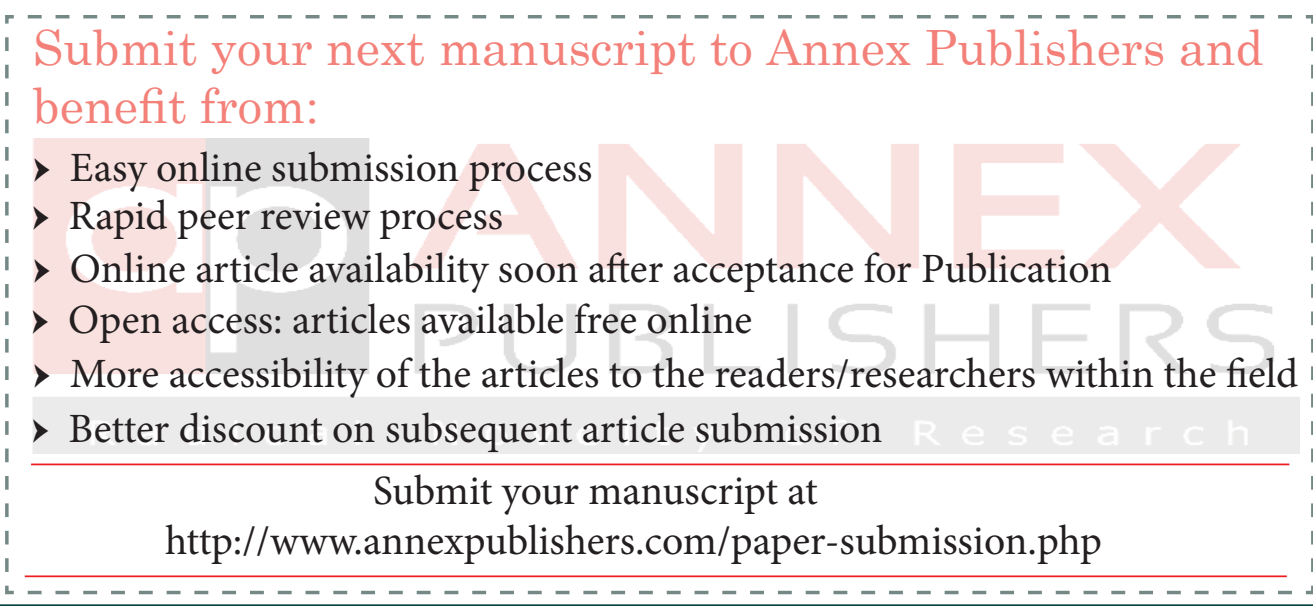

